\title{
BMJ Open \\ What do parents of children with dysphagia think about their MDT? A qualitative study
}

\author{
Emma Cowpe (Jebson), ${ }^{1}$ Ben Hanson, ${ }^{2}$ Christina H Smith ${ }^{3}$
}

To cite: Cowpe E, Hanson B, Smith $\mathrm{CH}$. What do parents of children with dysphagia think about their MDT? A qualitative study. $B M J$ Open 2014;4:e005934. doi:10.1136/bmjopen-2014005934

- Prepublication history and additional material is available. To view please visit the journal (http://dx.doi.org/ 10.1136/bmjopen-2014005934).

Received 19 June 2014 Revised 10 September 2014 Accepted 25 September 2014

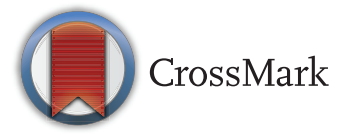

\footnotetext{
${ }^{1}$ Speech and Language Therapy, Royal Free Hospital, London, UK

${ }^{2}$ Department of Mechanical Engineering, University College London, London, UK ${ }^{3}$ Department of Language and Communication, Division of Psychology and Language Sciences, University College London, London, UK
}

Correspondence to Emma Cowpe; emma.cowpe1@nhs.net

\section{ABSTRACT}

Objectives: To seek the experiences and perspectives of parents caring for children with dysphagia, with emphasis on their experiences of working within their child's multidisciplinary team (MDT).

Setting: This research was completed in community settings, within families' homes across the UK.

Participants: 14 families self-selected to participate in the study. Criteria specified that participants must care for a child under the age of 18 and to decrease ambiguity the term 'diagnosis of dysphagia' was defined as the need for modified (thickened) fluids. Exclusion criteria: caring for an adult over the age of 18; diet and fluid modifications for reasons other than dysphagia (eg, for symptomatic treatment of gastro-oesophageal reflux disease. Participants were interviewed within their homes using a semistructured questionnaire and data was analysed using a descriptive phenomenological approach through use of thematic coding and constant comparison. Themes and relationships were inductively generated from the data.

Results: Participants universally expressed a desire to be involved with their child's MDT; this study identified the following facilitators and barriers to collaboration: accessing services, professional knowledge and professional skillset. Participants described three means of responding to these barriers: reacting emotionally, seeking solutions and making decisions.

Conclusions: This study recorded in-depth reports of participants' experiences of working with healthcare providers. Despite government-driven efforts towards person-centred healthcare and social care, participants shared accounts of times when this has not occurred, describing a negative impact on the well-being and quality of life of their child and family.

\section{BACKGROUND}

Swallowing difficulties (dysphagia) can vary in aetiology, symptomology and severity and affect children with a variety of medical diagnoses. Up to $90 \%$ of children with neurodevelopmental disorders such as cerebral palsy and Down syndrome experience signs of dysphagia including coughing, choking, chest infections, poor weight gain and breathlessness, ${ }^{1}$ often from birth or early infancy.
Strengths and limitations of this study

Evidence of facilitators and barriers to effective parent-professional collaboration.

- Provision of parents' own report of experiences with multidisciplinary teams

- Supports literature relating to the need for holistic, patient-centered care and provides skills and attributes required of professionals in multidisciplinary working.

- Small-scale study encouraging further research in this area.

- Self-selecting sample involving outside agencies in initial recruitment.

Children with gastro-oesophageal reflux disease (GORD) and those born prematurely are also at increased risk of childhood dysphagia. $^{2-4}$ Thus dysphagia can be a symptom of different underlying medical conditions and is diagnosed and treated by a variety of medical specialists.

Children with complex and pervasive needs require support in a range of inpatient and outpatient specialist settings including hospitals, clinics and schools. Children may be in contact with a range of health and care professionals including paediatricians, general practitioners (GPs), speech and language therapists, physiotherapists, dieticians and social workers; for these children and their families well-coordinated input is essential for provision of individualised care. ${ }^{5-7}$ Multidisciplinary teams (MDTs) are commissioned to provide joined up, patient-centred support and seek to place children and their families at the centre of decision-making processes. ${ }^{48}$ Government initiatives such as the Early Support keyworking scheme ${ }^{6}$ and the Common Assessment Framework $^{10}$ have been set up throughout the UK to improve care quality by providing a framework for regular MDT discussion; avoiding repetition of information and reducing carer burden; and providing a single point of contact for better coordination of care and support. ${ }^{6}$ 
A number of studies have explored parent experience of caring for children with dysphagia although typically research has focused on the needs of carers of children with complex needs which may or may not involve dysphagia as a symptom, ${ }^{11-15}$ or has been confined to specific settings such as schools $^{9} \quad 16{ }^{17}$ or Child Development Centres. ${ }^{18}$ Mahant et al, ${ }^{19}$ Craig et $a l^{20}{ }^{21}$ and Sullivan $e t a l^{22}$ have studied the experiences of parents of children requiring gastrostomy feeding; these studies highlighted the importance and value placed by parents on oral feeding, ${ }^{19} 22$ and acknowledged the complexities involved in decision-making when considering how to balance risks of oral intake with maximising quality of life (QoL) for children with dysphagia. ${ }^{19-21}$ Recommendations for practice include the need for good-quality information and support for families and the need for professionals to understand caregiver's perspectives and priorities and to adopt a model of partnership working with the families under their care. ${ }^{19-21} 23$ Studies looking at specialist feeding clinics within the USA and the $\mathrm{UK}^{24-27}$ describe the intricate and multifaceted nature of feeding and swallowing disorders and highlight the importance of multidisciplinary working to ensure holistic, child-centred and family-centred assessment, treatment and support. This paper seeks to build on this research and explore the issues pertinent to families caring for children with dysphagia in the UK, and to gain their perspectives on the care they have received.

\section{METHOD}

\section{Participants}

This cross-sectional study involved parents and carers of children with a diagnosis of dysphagia, aged between 2 and 11 years. Information about the study was distributed through special schools, charities and local and national support groups in the form of letters, online forums and newsletters. Parents self-selected by contacting the researcher based on the information provided, and gave written consent to participate in the study. Fifteen parents were initially recruited; one interview was discounted from analysis as the individual with dysphagia was 24 years old. Analysis was completed with interviews from 14 parents; the children's characteristics are summarised in table 1.

\section{Procedure}

Audiorecorded, in-depth interviews were considered the most appropriate form of data collection; providing participants with dedicated time and space to share their individual experiences and perceptions. ${ }^{28} 29$

Participants were contacted and interviews were scheduled at their convenience. Thirteen parents were interviewed at the family home and one parent was interviewed at her place of work. Although all participants consented to audiorecording, each parent was reminded of their right to withdraw from the study at any time. Given the emotive nature of the issues being discussed, breaks were offered throughout the interview process to enable a period of time 'off recording' if required. Informal discussion prior to and following each interview allowed for debriefing and reflection without participants feeling under pressure of being recorded.

Semistructured questionnaires formed the basis of interviews; this provided a degree of structure and standardisation in questioning while allowing for deviation from the 'script'. Adopting a semistructured approach allowed for more natural conversation during interviews, avoiding an overtly formal interview style and maximising the richness of each participants' account. ${ }^{30}{ }^{31}$ Given the sensitivity of the topics discussed, freedom to deviate from structured, formal questioning was essential. ${ }^{29}$ Parents were asked questions, including open/closed and content-mapping/dimension-mapping questions, ${ }^{29}$ to gain general and more specific information relating to their child's swallowing history, initial support received, ongoing needs and current support. Interviews took approximately $1 \mathrm{~h}$ and each audiorecording was transcribed prior to analysis.

The researcher kept a journal for additional notes throughout the data collection process. ${ }^{28} 32{ }^{29}$ Although journal entries were not formally used in data analysis, they were used to document preliminary codes and themes that began to emerge at the time of each interview, as well as notes on follow-up questions that had been asked, and general attitudes of interviewees at the time (eg, positivity/negativity). ${ }^{29}$

\section{Analysis}

Interviews were transcribed and returned to participants to verify accuracy. Two parents made minor clarifications to comments within their manuscript; one parent providing further detail of the chronology of her daughter's medical interventions and another providing the full name of their child's thickener. The parent's amendments were recorded prior to coding.

Qualitative analysis methods were identified as most appropriate for this data set, given the richness of participants' accounts and the complexity of issues discussed. ${ }^{19}$ Descriptive phenomenology was selected in order to best describe participants' experiences and to uncover common themes within and between participants' accounts. ${ }^{33}$ Methods of thematic coding and constant comparison were employed to generate codes inductively from the data, rather than impose preconceived themes constructed by the researcher. ${ }^{28}{ }^{34} \mathrm{In}$ turn, the codes that emerged led to the construction of themes. During coding a transcript was selected at random and manually coded line by line with short phrases summarising each 'unit'; examples included negative emotions, creative problem solving and service flexibility. Units varied in length; comprising of phrases, sentences or a number of lines, with one code applied to each unit. 
Table 1 Individual child characteristics

\begin{tabular}{|c|c|c|c|c|}
\hline $\begin{array}{l}\text { Parent ID } \\
\text { number }\end{array}$ & Medical diagnoses & $\begin{array}{l}\text { Age at diagnosis of } \\
\text { dysphagia }\end{array}$ & Nutritional intake & $\begin{array}{l}\text { Route to } \\
\text { recruitment }\end{array}$ \\
\hline 1 & CP epilepsy, GORD & Under 1 year & Oral diet & School \\
\hline 2 & Lissencephaly & 18 months & Oral diet & School \\
\hline 3 & No diagnosis & 8 months & Oral diet & School \\
\hline 4 & $\begin{array}{l}\mathrm{CP} \text {, hydrocephalus, epilepsy, } \\
\mathrm{VI}, \mathrm{HI}\end{array}$ & Under 1 year & PEG plus oral tastes & School \\
\hline 5 & $\begin{array}{l}\text { CP, chronic lung disease, } \\
\text { GORD }\end{array}$ & 1 year & $\begin{array}{l}\text { Oral diet (previously } \\
\text { PEG) }\end{array}$ & School \\
\hline 6 & Alagille syndrome & Under 1 year & Half oral, half PEG & School \\
\hline 7 & $\mathrm{DS}, \mathrm{CHD}$ & Under 1 year & Oral diet & Charity \\
\hline 8 & DS, GORD & 5 years & Oral diet & Charity \\
\hline 9 & $\begin{array}{l}\text { Congenital cytomegalovirus, } \\
\text { GDD }\end{array}$ & 1 year & Oral diet & Family worker \\
\hline 10 & $\mathrm{DS}, \mathrm{CHD}, \mathrm{GORD}, \mathrm{HI}$ & Under 1 year & Oral diet & Charity \\
\hline 11 & DS & Under 1 year & Oral diet & Charity \\
\hline 12 & DS & Under 1 year & $\begin{array}{l}\text { Oral diet (previously } \\
\text { PEG) }\end{array}$ & School \\
\hline 13 & DS, GORD, VI, HI & 2.5 years & Oral diet & School \\
\hline 14 & $\begin{array}{l}\text { DS, Hirschprung's disease, } \\
\text { GORD }\end{array}$ & 3 years & Oral diet & Charity \\
\hline
\end{tabular}

Additional transcripts were then added to the set and manually coded, with codes being continually compared within and between scripts and amended where required. ${ }^{28}$ As analysis progressed codes were grouped into broader themes. For reliability of the coding, 25\% of the coded transcripts were validated by an independent researcher with experience in qualitative data analysis.

\section{RESULTS}

Fourteen participants completed the study; participants cared for a child between the ages of 2 and 11 years; mean age 5.8 years. Of the 14 participants involved, 12 were under the care of a paediatrician when their child's swallowing difficulties were first investigated; 13 had contact from a speech and anguage therapist; 8 from physiotherapy; 8 from dietetics and 7 were seen by an occupational therapist. Eight families had contact from a health visitor; eight from the GP; four had involvement from school or nursery staff; one family had input from a school nurse and one from respite staff.
One overriding theme emerged from the data, present in all 14 interviews: all parents and carers expressed their desire to be involved in their child's care through close involvement in the MDT. Three subthemes emerged relating to factors particularly facilitating or hindering their ability to be involved within the MDT. A further three subthemes emerged as parents described their responses to the barriers they have experienced (figure 1). Participants' quotes are provided verbatim alongside their identifying number as allocated in table 1 .

\section{Being involved within the MDT}

Without exception, parents reported a desire to be recognised as a key member of their child's MDT. Parents valued the specialist knowledge and opinion of healthcare professionals, but wanted to be identified as the expert about their child.

My son is my number one subject. ${ }^{14}$

I'm the one dealing with it everyday. If you want to ask something it's better to ask me. ${ }^{10}$
Figure 1 Themes and subthemes generated from data.

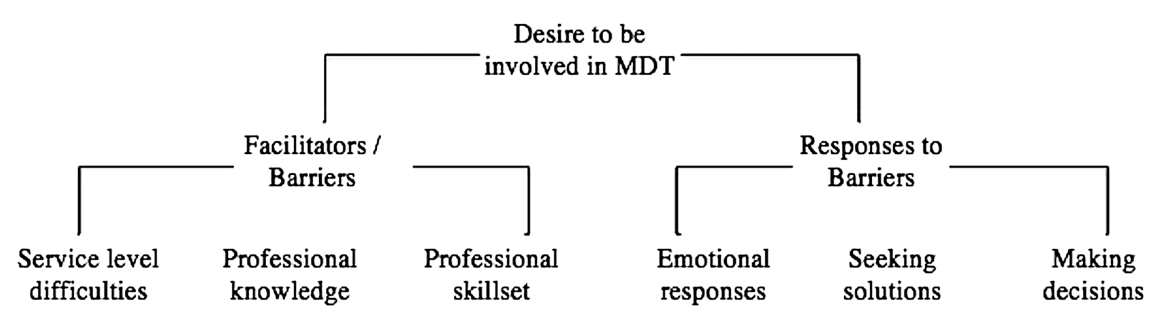


We know our children better than [professionals] do as individuals; they have to take our views on board and respect our opinions. ${ }^{7}$

\section{Facilitators and barriers}

The facilitators and barriers to parents' collaboration with the MDT were categorised into three separate subthemes: (1) accessing services, (2) professional knowledge and (3) professional skillset, as below:

1. Accessing services

Parents described three main issues around their ability to access services; time, staffing and flexibility of service delivery. When asked how satisfied they were with the support they had received for their child's dysphagia, nine parents reported some degree of dissatisfaction with service accessibility and availability.

They won't come and see him at home, which is a real shame. $^{2}$

My daughter was ill for the whole winter. [The community Speech and Language Therapist] came as a favour to check her swallow, but there's a fine line now she's in school, with whose remit it is. ${ }^{12}$

They said they didn't have enough staff [in hospital] to give support with her feeding. ${ }^{3}$

It was quite a few years before they had a permanent Speech and Language Therapist at school. ${ }^{4}$

Those who had felt largely satisfied with their support acknowledged the same qualities as important; reporting easier access to help and advice due to flexibility and availability of health and care staff.

The [respiratory] physios are really good. They come in [if she is unwell] and monitor her sats. It saves going to $\mathrm{A} \& \mathrm{E}$ and they take swabs that can be sent off. ${ }^{5}$

When we went for the Videofluoroscopy the Speech and Language Therapist came with us...Every six weeks she comes here to see him. ${ }^{7}$

We're lucky that we have had support. They're always at the other end of the phone if we need it. ${ }^{11}$

We have much more support now. ${ }^{10}$

\section{Professional knowledge}

Parents attributed their health and care professionals with a level of expertise and specialist knowledge; however, some parents felt that this knowledge was poorly demonstrated by professionals at crucial time points when it was needed; particularly in the early stages of seeking support and specialist advice for their child. Five parents received misdiagnoses of their child's dysphagia, which resulted in a wait of up to 5 years for an accurate diagnosis and to receive specialist intervention.
I kept showing her feeding to so many different consultants and no one spotted it ...they kept saying 'it's a virus, she's fine'. Thirteen times in her first year she was on antibiotics for chest infections. ${ }^{3}$

I'm surprised the paediatrician didn't signpost [specialist assessment] more clearly; she knew what [Lissencephaly] was and its implications. ${ }^{2}$

I just couldn't believe it took them so many years to take it seriously; it amazed me. ${ }^{8}$

Those with positive experiences also highlighted the importance of well-demonstrated expert knowledge. These families reported an increase in their knowledge of their child's condition as a result.

[The specialist's] advice, which I found useful was that there were three things to look at: if he was getting pneumonias...if he was failing to thrive...or if it as taking a very long time to feed him. ${ }^{2}$

[The specialist] had lots of questions; over the phone I was talking to her and she said my daughter had reflux and dysphagia, just from the phone call. ${ }^{8}$

\section{Professional skillset}

Parents provided a list of qualities they value in healthcare professionals (table 2), placing the greatest importance on communication skills. Parents valued professionals who demonstrated a willingness to listen and who actively sought their opinions.

Parents have the answers even if we don't have the terminology. ${ }^{12}$

More the medical side than the community side have no respect or value for what the parents have to say...it's quite nice when you find people who actually listen. ${ }^{10}$

The interpersonal (skills) are as important as the clinical (skills). ${ }^{13}$

Parents also described the importance of a positive working relationship between healthcare professionals, themselves and their child:

In the medical profession it'd hurt me when they wouldn't even address my son at appointments; they would talk to me about him, in front of him, without even saying hello. ${ }^{2}$

[I value] people that are good at interacting with my daughter...people who work with her rather than just talking to mum. ${ }^{3}$

Every six weeks [our Speech and Language Therapist] comes here to see [my son] ... he really likes her. ${ }^{7}$

Parents with negative experiences described times when they felt unheard and 'on a different page' to professionals. Parents raised concerns that too strong a 
Table 2 Valued professional qualities

\begin{tabular}{ll}
\hline ID number & Qualities listed \\
\hline 1 & Accessible; two-way communication; being honest without being too negative \\
2 & Flexibility in appointments; listening and walk alongside you; treating you as a thinking person; addressing my \\
& son at appointments \\
3 & Interacting with my daughter; working well with other professionals; following through with what they say; talking \\
& to who they say they will; when you feel they want to help you and are on your side; making notes and giving \\
& you copies; being contactable; being approachable; being honest; not being overworked \\
4 & Being there; being contactable; liaising with each other; being trustworthy \\
5 & Being caring, friendly; knowing my child so I don't need to repeat myself; record keeping \\
6 & Good people skills, sensitive to my child's needs and my concerns; good communication; sympathy; seeing my \\
7 & child as an individual \\
8 & Listen and take the parents' views seriously; communication with parents; explaining jargon; sharing information \\
9 & Showing expertise in their field; treating children as individuals; not labelling children \\
10 & Professionals working together; putting my child first; sharing information \\
11 & Approachability; being able to explain things \\
12 & Honesty; encouragement; new ideas; continuity \\
13 & Approachability; friendliness; warms; engaging our child; active, unhurried listening; empathy \\
14 & Asking questions of me; active listening; acting on what we say; not labelling our child
\end{tabular}

focus was placed on health and risk, at times to the detriment of their child's emotional well-being and QoL.

I felt that [the professionals] were very risk-averse...their first concern was to ensure the risk was minimized completely and utterly, rather than recognising that there was a risk but that it wasn't too great yet. ${ }^{2}$

We told school that if the children are having any treats, our daughter can have them too... There was an event where all the children were having hot chocolate with marshmallows. They wouldn't let our daughter have one and she got upset. ${ }^{8}$

Parents discussed the importance of information sharing, identifying a need for up-to-date, jargon-free information to maximise their understanding and involvement. Parents reported a similar need for more effective information sharing between professionals within the MDT. Parents identified times when poor collaboration had negatively impacted on the well-being of their child or on themselves as caregivers.

[The professionals] don't liaise with each other at all... although they are all in the same building. ${ }^{4}$

I repeat myself all the time...it's hard to keep bringing up the past. ${ }^{5}$

In school there is a lack of communication... at one time they had stopped feeding her. I felt so upset by it. ${ }^{6}$

\section{Responses to barriers}

Parents' responses to the challenges they have faced were summarised in the following themes: (1) reacting emotionally, (2) seeking solutions and (3) making decisions.

\section{Reacting emotionally}

Parents who encountered barriers to support had reported high levels of anxiety, frustration and distress and feelings of being unheard. Parents who experienced difficulties at the early stages of their child's care described associated feelings of guilt and helplessness at their child's failure to thrive, and frustration in their search for answers. All parents with these experiences reported a significant impact on their emotional well-being.

I struggled with it; it was awful. It made me extremely depressed because I just didn't know what was going on, and no one seemed to be paying any attention. ${ }^{3}$

I felt that this was very poorly handled in terms of the emotional impact it can have on a parent, to say you might not be able to feed your child yourself. ${ }^{2}$

[The Speech and Language Therapist] was only focussed on communication. She asked us every time how feeding was going; I dreaded her asking me that...I hated telling her he just couldn't eat, but she just said to keep trying. It was so demoralising... ${ }^{13}$

\section{Seeking solutions}

All parents described times when they had adopted a proactive approach towards seeking and receiving help: researching into their child's medical conditions, recommended treatment, medication and available support. Parents report using the knowledge they had gained to actively request or refuse specific services or interventions.

It's been more parent-driven; no one takes ownership of the problems. ${ }^{13}$ 
Things take a long time. I work with children with disabilities and have some knowledge, but even with knowledge you need to do a lot of pushing. ${ }^{10}$

Parents reported the value of peer support and identified times when they have felt empowered by the knowledge they have gained from other parents and carers in a similar situation.

At first I didn't want a PEG but...I spoke to other parents who said they're really good. ${ }^{6}$

It's been useful meeting other parents, to talk about things with them and share experiences. ${ }^{11}$

I wrote to the GP and asked [for thickener], because somebody else used it and gave me some sachets. ${ }^{1}$

Talking to other parents [helps] too, not just professionals. $^{4}$

Some parents used the knowledge they had gained to directly challenge professional advice or seek second opinions; six parents contacted private professionals for second opinions and two families contacted overseas specialists for advice.

I see a private person because I'm unhappy with the support I get. ${ }^{3}$

I discovered a Speech and Language Therapist in Brazil... she said my daughter has [dysphagia]...I was shocked; she'd had problems all that time and we had been told it was nothing. ${ }^{8}$

\section{Making decisions}

Parents described times when they had taken matters 'into their own hands' in the day-to-day management of their child's difficulties. Parents reported developing their own strategies based on a 'trial and error' approach with their child; employing a range of techniques to maximise their child's swallowing safety. Techniques included postural adaptations, changes to mealtime utensils and environmental strategies.

We had been spoon-feeding him water...he was alright with spoonfuls; any more and he coughs. ${ }^{5}$

She would have rice pudding and I would give her a dummy after to help her swallow...when we put the dummy in then she would initiate the swallowing action. ${ }^{6}$

I take her drink away for a second [between sips] to give her a chance to breathe before carrying on. ${ }^{10}$

A similar approach was used to manage difficulties encountered with fluid thickeners. Parents reported a range of difficulties using thickeners on an everyday basis including lumpiness; problems maintaining fluid consistency over time; managing liquid medications and modifying their child's diet or fluid consistency when unwell or tired. Parents described a number of techniques that they developed using their knowledge and experience of their child, in order to avoid such difficulties.

We use a lower dose [of thickener] in milk, it's just enough to slow it down. In his juice we use slightly more because the cups have bigger holes in. ${ }^{7}$

We recognise when it needs to be thicker, like when she's poorly. ${ }^{13}$

We do thicken some of his medication... we give medication in a syringe too so we can control how he has it. ${ }^{11}$

\section{DISCUSSION}

This study proceeded with explorative aims to seek parents' experiences of their involvement with their MDT. As a qualitative study this does not seek to generalise findings to the wider population, particularly considering the age ranges of children involved and the geographical spread. Qualitative methodologies employed were deemed appropriate for a study of its size and nature. ${ }^{34} 28$ Reliability and validity were established during analysis through inter-rater agreement and participant validation.

Participants acknowledged the need for multidisciplinary working to ensure holistic management of their child's difficulties, as reported elsewhere within the literature. ${ }^{23-27} 35$ Parents encountered a number of barriers to accessing appropriate services in the early stages of their child's life and described a range of negative physical and emotional effects on themselves and their children. While resources may be limited, improved staffing and time for direct family support may have reduced the impact of these barriers. Shared resources such as shared workspaces for health professionals may serve to improve collaboration and reduce carer burden. More flexible models of service delivery, such as improved crossover between school and community services, may have enabled some families to access support quicker and encounter fewer moments of delay and procedural 'red tape'.

Families who received repeated misdiagnoses of their child's condition described higher levels of dissatisfaction in the MDT and negative impacts on child and family health and well-being. Participants reported their frustration and upset in knowing there was 'something wrong' with their child's health yet failing to receive appropriate support and diagnostics. It could be argued that the parents who sought second opinions from private and overseas professionals, did not receive advice that could not have been provided by their child's MDT.

Participants expressed their need for healthcare professionals to work proactively, particularly in the early stages of seeking and receiving a diagnosis of dysphagia. Previous work has shown that professionals who work holistically and proactively are better able to anticipate a 
child's needs, referring for specialist intervention before a critical need arises. ${ }^{35}$ Parents acknowledged the importance of communicative and interpersonal skills in facilitating a trusting relationship between family members and professionals, particularly when balancing considerations around risk and QoL. This issue was particularly pertinent for parents caring for children considered for percutaneous endoscopic gastrostomy feeding; an issue requiring great sensitivity and discussed elsewhere in the literature. ${ }^{20} 2136$ The need for good-quality information was highlighted to enable informed decision-making ${ }^{23}$ and effective communication was considered to reduce the burden on parents to repeat their child's medical information to different members of the MDT. $^{37}$ Keyworking schemes such as Early Support ${ }^{5} 6$ and shared documentation may be one step towards this end in order to streamline communication and to provide a single point of contact for families caring for children with complex needs; however with current financial and structural changes to the healthcare and social-care system such resources may be limited.

The emotional, financial and physical burdens of caring for a child with a disability are well reported. ${ }^{11-13}$ Parents reported a significant impact on the emotional and physical well-being of themselves and their children, acknowledging a need for proactivity on the part of the MDT, particularly in the early stages of receiving diagnoses and requesting specialist support. Parents utilised a range of creative approaches in managing the everyday difficulties of using thickening agents ${ }^{38}$ and drew on the experiences of themselves and others to develop solutions that worked for them.

Limitations: As a self-selecting cohort the sample in this study is open to a degree of bias. ${ }^{39}$ Because other agencies such as schools, charities and support groups were involved in disseminating the information a response rate could not be calculated as it was unclear how many parents had come into contact with the initial information regarding the study. Social demographics were not taken for this study; further research exploring the experiences of socially isolated families would be beneficial. Parents were invited to check the accuracy of transcripts; this feature of the study was not accounted for in the initial stages and as such may have been considered an additional burden which had not been anticipated by parents at the recruitment stage.

Further developments of this research exploring in more depth the different types of service provided to families with children with dysphagia would be beneficial. Similarly although social demographics were not taken for this study's further research, this study could be expanded by studying socially isolated or 'hard to reach' families.

Acknowledgements The authors acknowledge all parents who participated and the schools and organisations that provided information to appropriate parents. The authors also acknowledge the help of $J$ Wood for advice regarding qualitative analysis, and A Dixon-Dewfall as an independent coder during data analysis.
Contributors EC and CHS accessed the data for the study in its entirety prior to and during write-up; $\mathrm{BH}$ contributed to the conception and design of the study, critical revision of draft versions of manuscript and approval of final version. EC was responsible for participant recruitment, data collection and analysis, write-up of manuscript and had access to all data. CHS contributed towards research design, provided advice and supervision on research processes and data write-up, and critically revised and approved the manuscript (draft and final versions).

Funding This research received no specific grant from any funding agency in the public, commercial or not-for-profit sectors.

Competing interests None.

Ethics approval The study protocol and consent procedure were approved by the local institution research ethics committee (LC/2011/007); University College London.

Provenance and peer review Not commissioned; externally peer reviewed.

Data sharing statement No additional data are available.

Open Access This is an Open Access article distributed in accordance with the Creative Commons Attribution Non Commercial (CC BY-NC 4.0) license, which permits others to distribute, remix, adapt, build upon this work noncommercially, and license their derivative works on different terms, provided the original work is properly cited and the use is non-commercial. See: http:// creativecommons.org/licenses/by-nc/4.0/

\section{REFERENCES}

1. Schwarz M. Feeding disorders in children with developmental disabilities. Infants Young Child 2003;16:317-30.

2. Wolf $\mathrm{L}$, Glass R. Feeding and swallowing disorders in infancy: assessment and management. San Antonia: Therapy Skills Builders, 1992

3. Vohr B, Wright LL, Poole WK, et al. Neurodevelopmental outcomes of extremely low birth weight infants $<32$ weeks' gestation between 1993 and 1998. Pediatrics 2005;116:635-43.

4. Bell H, Sheckman Alper B. Assessment and intervention for dysphagia in infants and children: beyond the neonatal intensive care unit. Semin Speech Lang 2007;28:213-22.

5. Department for Education and Skills, Department of Health. National Service Framework for Children, Young People and Maternity Services: Disabled Children and Young People and those with Complex Health Needs. 2004. https://www.gov.uk/government/ uploads/system/uploads/attachment_data/file/199952/National_ Service_Framework_for_Children_Young_People_and_Maternity Services_-_Core_Standards.pdf

6. Department for Education and Skills. Aiming high for disabled children: better support for families. 2007. http://webarchive. nationalarchives.gov.uk/20130401151715/http://www.education.gov. uk/publications/eOrderingDOwnload/PU213.pdf (accessed May 2014).

7. Lewis M. Better Care, Better Lives: Improving outcomes for children, young people and their families living with life limiting and life threatening conditions. Department of Health, 2008. http://eprints. uwe.ac.uk/5178/1/Download.pdf

8. Reeves S, Perrier L, Goldman J, et al. Interprofessional education: effects on professional practice and healthcare outcomes. Cochrane Database Syst Rev 2013;3:CD002213.

9. Angell M, Bailey R, Stoner J. Family perceptions of facilitators and inhibitors of effective school-based dysphagia management. Lang Speech Hear Serv Sch 2008;39:214-26.

10. Department for Education and Skills. Every Child Matters. 2003. http://webarchive.nationalarchives.gov.uk/20130401151715/http:// www.education.gov.uk/publications/eOrderingDownload/CM5860.pdf

11. Raina $\mathrm{P}, \mathrm{O}$ 'Donnell M, Rosenbaum $\mathrm{P}$, et al. The health and well-being of caregivers of children with cerebral Palsy. Pediatrics 2005;115:626-36.

12. Roberts K, Lawton D. Acknowledging the extra care parents give their disabled children. Child Care Health Dev 2001;27:307-19.

13. Fisher $\mathrm{H}$. The needs of parents with chronically sick children: a literature review. J Adv Nurs 2001;36:600-7.

14. Meester-Delver A, Beelen A, Hennekam R, et al. Predicting additional care in young children with neurodevelopmental disability: a systematic review. J Adv Nurs 2001;36:600-7.

15. Cass H, Price K, Reilly S, et al. Supporting children with multiple disabilities. Child Care Health Dev 1999;25:191-211. 
16. Arvedson J, Homer E. Managing dysphagia in the schools. ASHA Leader 2006;11:8-30.

17. Harding $C$, Halai V. Providing dysphagia training for carers of children who have profound and multiple learning disabilities. $\mathrm{Br} \mathrm{J}$ Dev Disabil 2009;55:33-47.

18. Burland L. Feeding issues in children with neurodevelopmental difficulties: implementation of nutritional care and dysphagia guidelines at St James University Hospital Child Development Centre. Dev Med Child Neurol 2011;53:44-5.

19. Mahant S, Jovcevska V, Cohen E. Decision-making around gastrostomy-feeding in children with neurologic disabilities. Pediatrics 2011;127:e1471-81.

20. Craig G, Scambler G, Spitz L. Why parents of children with neurodevelopmental disabilities requiring gastrostomy feeding need more support. Dev Med Child Neurol 2003;45:183-8.

21. Craig G. Psychosocial aspects of feeding children with neurodisability. Eur J Clin Nutr 2013;67:S17-20.

22. Sullivan P, Juszczak E, Bachlet AM, et al. Impact of gastrostomy tube feeding on the quality of life of carers of children with cerebral palsy. Dev Med Child Neurol 2004;46:796-800.

23. Stoner J, Bailey R, Angell M. Perspectives of parents/guardians of children with feeding/swallowing problems. J Dev Phys Disabil 2006:333-53.

24. Puntis JW. Specialist feeding clinics. Arch Dis Child 2008;93:164-7.

25. Ayoob KT, Barresi I. Feeding disorders in children: taking an interdisciplinary approach. Pediatr Ann 2007;36:478-83.

26. Simonsmeier V, Rodriguez M. Establishment of an interdisciplinary pediatric Oral-Motor-Sensory feeding clinic team. Infants Young Child 2007:20:345-54.

27. Martin C, Southall A, Shea E, et al. The importance of a multifaceted approach in the assessment and treatment of childhood feeding disorders: a two-year-old in-patient case study in the U.K. National Health Service. Clin Case Stud 2008;7:79-99.

28. Silverman D. Doing qualitative research. 2nd edn. London: Sage, 2005.

29. Ritchie J, Lewis J. Qualitative research practice: a guide for social science students and researchers. London: Sage, 2003.

30. Denzin N, Lincoln Y. Collecting and interpreting qualitative materials. London: Sage, 1998.

31. Walliman N. Research methods: the basics. London: Routledge, 2011.

32. Meloy J. Writing the qualitative dissertation. Lawrence Elbaum, 1994.

33. Reiners G. Understanding the Differences between Husserl's (Descriptive) and Heidegger's (Interpretive) Phenomenological Research. J Nurs Care 2012. doi:10.4172/2167-1168.1000119

34. Sandelowski M. Whatever happened to qualitative description? Res Nurs Health 2000;23:334-40.

35. Arvedson J. Assessment of pediatric dysphagia and feeding disorders: clinical and instrumental approaches. Dev Disabil Res Rev 2008;14:118-27.

36. Petersen MC, Kedia S, Davis $\mathrm{P}$, et al. Eating and Feeding are not the same: caregivers' perceptions of gastrostomy feeding for children with cerebral palsy. Dev Med Child Neurol 2006;48: 713-17.

37. Dick J. 'Dysphagia severity score' System: clinical outcomes in paediatric dysphagia. Int J Lang Commun Disord 1998;33 (S1):268-72.

38. Smith C, Jebson E, Hanson B. Thickened fluids: investigation of users' experiences and perceptions. Clin Nutr 2014;33:171-4.

39. Polgar E, Thomas S. Introduction to research in the healthcare sciences. 4th edn. London: Elsevier, 2000. 